\title{
Artificial cervical disc replacement: Principles, types and techniques
}

\author{
L. H. S. Sekhon, J. R. Ball
}

SpineNevada, Reno, Nevada, U.S.A. Department of Neurosurgery and Spinal Injuries Unit, Royal North Shore Hospital, University of Sydney, Sydney, NSW, Australia

\begin{abstract}
Cervical arthroplasty after anterior decompression with insertion of a prosthetic total disc replacement has been suggested as an alternate to anterior cervical fusion. Currently there are four cervical arthroplasty devices available on the market whose results in clinical use have been reported. Each device varies in terms of materials, range of motion, insertion technique and constraint. It is not known which device is ideal. Early studies suggest that in the short term, the complication rate and efficacy is no worse than fusion surgery. Long-term results have not yet been reported. This review examines the current prostheses available on the market as well as discussing issues regarding indications and technique. Pitfalls are discussed and early experiences reviewed. In time, it is hoped that a refinement of cervical arthroplasty occurs in terms of both materials and design as well as in terms of indications and clinical outcomes as spinal surgeons enter a new era of the management of cervical spine disease.
\end{abstract}

Key words: Arthroplasty; Bryan ${ }^{\circledR}$; cervical; fusion; surgery

Placement of an artificial disc prosthesis, after performing an anterior cervical decompression, is an emerging technology that is changing the approach to cervical spine pathology. In contrast to previous fusion techniques, arthroplasty aims to preserve cervical motion, thus preventing complications associated with rigid arthrodesis and subsequent segmental loss of motion. Several prostheses, now available for clinical use, use different materials and design in their manufacture. Clinical series reporting early results with these implants are appearing. Reports of shortcomings as well as successes are also being described. With at least five cervical arthroplasty devices and a similar number of lumbar prostheses, refinement of indications and an understanding of the importance (or lack there of) of current design features is the next short to medium term goal. Ultimately, only long-term follow up will show whether the shortcomings of fusion surgery have been adequately addressed or whether new, previously unrecognized problems will occur with preservation of motion.

\section{History and rationale}

Historically, anterior approaches in the cervical spine have included anterior cervical discectomy alone (ACD), anterior cervical discectomy with fusion (ACDF) and ACDF with anterior plating. ${ }^{[1]}$ The substrate for fusion has included autograft, often from the iliac crest, human or animal allograft or more recently, bone graft substitutes and osteogenic factors. Postoperative immobilization in a cervical collar may be required. Whilst the primary clinical endpoint is the relief of neural compromise through adequate decompression, an additional surgical aim has been to achieve solid bony fusion. Failure of fusion resulting in pseudarthrosis is reported to occur in up to $20 \%$ of cases. ${ }^{[2]}$ This can be associated with increasing or persistent pain, neurologic deficit and/or the development of spinal deformity. Successful fusion may avoid these potential downsides, but the fusion of two vertebral bodies eliminates a spinal motion segment and mounting evidence suggests this may be detrimental, with biomechanical studies report increased stress/strain at levels adjacent to a fused segment. ${ }^{[3,4]}$ In clinical studies, adjacent segment degeneration has been demonstrated in $2.9 \%$ of patients with fusion; giving an actuarial 10 years risk of $25.6 \%,{ }^{[5]}$ with the implication that at least one in four patients who undergo a successful cervical fusion will need further surgery for accelerated adjacent segment disease at some time in the future. It has been argued that this relatively high figure of further surgery may actually reflect the likely outcome of accelerated disc degeneration in this subtype of patient, predisposed to disc degeneration; that they would have developed adjacent degeneration with or without fusion surgery. In response to this claim, a study by Goffin et al. examined the radiological incidence of adjacent segment degeneration in patients undergoing fusion for trauma compared with nontraumatic degenerative 
disease. ${ }^{[6]}$ They found degenerative progression occurred in both groups suggesting that adjacent segment disease cannot solely be attributed to the natural history of degenerative disease.

Cervical disc replacement preserves motion after decompression with the aim of preventing adjacent segment stress. It also avoids the morbidity associated with cervical immobilization and autologous bone graft harvesting and eliminates the potential infective risks associated with allograft bone. ${ }^{[7]}$

Intervertebral disc arthroplasty is a concept that was first described in the $1960 \mathrm{~s}$, when Fernstrom placed stainless steel intercorporal endoprostheses between adjacent vertebra. ${ }^{[8]}$ The majority of prostheses were placed in the lumbar spine but 13 cervical arthoplasties in eight patients were reported. Reitz and Joubert subsequently reported on their experience with 75 cervical prostheses in 32 patients. ${ }^{[9]}$ No further reports of this prosthesis were published and the placement of these devices was abandoned after problems with device subsidence and segmental hypermobility. Subsequently, the development of new cervical prostheses has been slower than that seen in the lumbar spine. The rapidly expanding modern experience with cervical disc arthroplasty was initiated with the reported implantation of an artificial cervical joint in 20 patients. ${ }^{[10]}$ Known as the Cummins-Bristol joint, it was a two piece, stainless steel, metal-on-metal, ball in socket construct secured to the anterior vertebral body by screws. This device was manufactured in one uniform size, unable to be adapted to individual anatomy, and had a bulky profile. At followup, 16 of 18 patients demonstrated radiographic evidence of preserved intervertebral motion. Excessive disc space distraction to accommodate the prosthesis with consequent facet joint separation was proposed as the cause of failure. Symptomatic improvement was reported in 16 of 20 patients. Several incidents of screw breakage and pullout led to the number, placement and design of the screws being varied. Despite these problems, this pioneering study demonstrated the feasibility of cervical arthroplasty.

\section{Design principles and available prostheses}

Cervical arthroplasty prostheses should aim to maintain the normal range and type of intervertebral motion while transmitting axial loading forces from the vertebral body above to the one below. The design of modern intervertebral disc replacements can therefore be classified in terms of how the prosthesis allows motion and how it relates to the adjacent vertebral body. These two broad traits are further broken down into the issues of articulation and kinematics, integration and fixation and materials. ${ }^{[1]}$ The key features of the commonly available devices are summarized in (Table 1).

\section{Articulation and kinematics}

Normal motion between two vertebral bodies occurs around a point described as the 'instantaneous centre of rotation'. Whilst the location of this point varies between levels, it is generally situated in the posterior half of the upper portion of the inferior vertebral body. Interbody motion is not a pure rotation and involves a degree of translation. The location of the centre of rotation of a prosthesis should attempt to mimic the natural situation. The constraint of the prosthesis is the degree to which it allows movement other than uniaxial rotation. ${ }^{[12]}$ A device can be constrained, semiconstrained or unconstrained in a description of the motion that the device allows relative to other devices and normal motion.

\section{Integration and fixation}

Stability of the device is divided into an initial stability that relies on some form of constraining mechanism and long-term stability that typically implies osteointegration of the device into surrounding bone. The interface between prosthesis and vertebra should allow transmission of axial forces between adjacent vertebrae. A broad surface of contact, promotion of bony in-growth and a similar modulus of elasticity facilitates this aim. Short- and long-term fixation should provide for aim to prevent subluxation, subsidence, displacement or dislocation.

\section{Materials}

The choice of material for a prosthesis should consider the needs of both the articulating surface and the interface between prosthesis

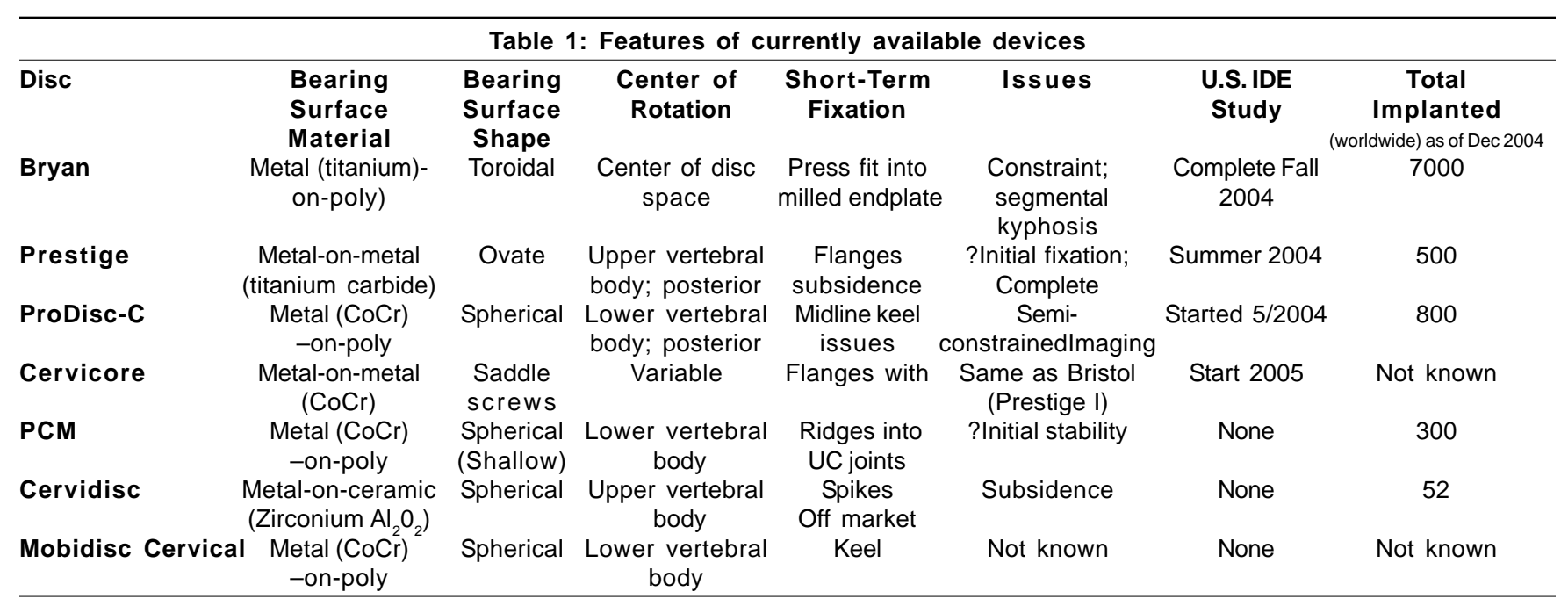


and vertebral body. ${ }^{[13]}$ Significant knowledge gained in the development of diarthodial synovial joint replacements (hip and knee) has been translated to the manufacture of arthroplasty prostheses. Articular surfaces may involve a metal-on-metal, metalon-polymer (poly), ceramic-on-poly or ceramic-on-ceramic interface. The polymers used have been ultra high molecular weight polyethylene (UHMWPE) or polyurethane. Metal components have been produced from titanium, stainless steel or chromium, often as an alloy to decrease corrosion. These may wear more slowly than UHMWPE. Coating of the vertebral interface surface to encourage bone in-growth has utilized several materials including calcium phosphate, hydroxyapatite and porous titanium. The material used can also affect the ability to image both the prosthesis and the adjacent neural tissues postoperatively (see below).

The Bryan ${ }^{\circledR}$ (Medtronic Sofamor Danek, Memphis, TN, USA) cervical disc prosthesis (Figure 1) was first described in clinical use by Goffin et al ${ }^{[14]}$ and subsequently by Sekhon. ${ }^{[15]}$ It consists of a polyurethane nucleus designed to fit between two titanium alloy surfaces (shells). It is a bi-articulating unconstrained device with a fully variable instantaneous axis of rotation. A polyurethane sheath surrounds the nucleus and is attached to the shells with titanium wire, forming a closed compartment that may contain any wear debris and prevent soft tissue in-growth. Titanium alloy seal plugs provide for retention of a sterile saline lubricant. Initial stability is achieved by precision milling of the vertebral end plates, and long-term stability is provided by bone growth into the porouscoated titanium alloy end plates. Anterior flanges on each shell help to prevent posterior migration of the device as well as facilitating insertion of the device. The prosthesis is presently designed in five diameters: $14,15,16,17$, and $18 \mathrm{~mm}$. There is only one height. The insertion technique involves multiple steps and is complex, allowing for precise placement of the prosthesis and preparation of endplates. This device is the most implanted device worldwide with over 7000 implanted over the past 4 years.

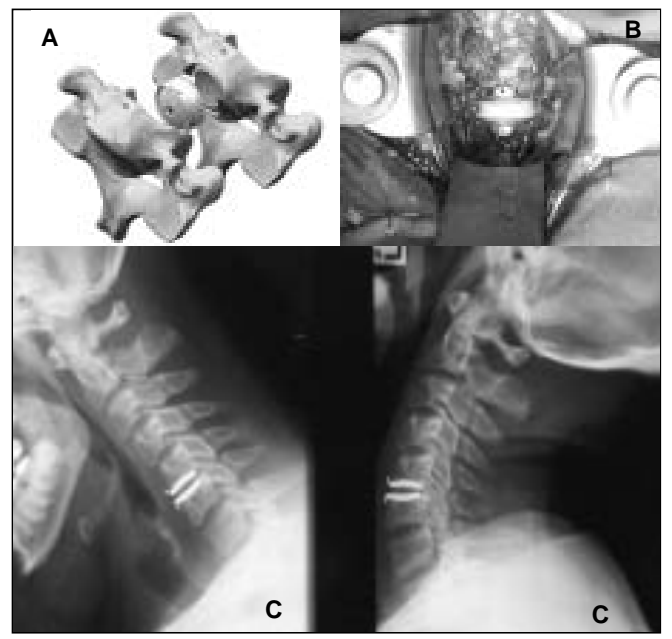

Figure 1: The Bryan ${ }^{\circledR}$ cervical disc prosthesis is a compressible unconstrained prosthesis which attains initial fixation through a press fit relationship with the end plates (A). An intraoperative view (B) shows no additional fixation is needed. Postoperative flexion (C, left) and extension ( $C$, right) show good postoperative motion
The device is relatively unconstrained, which has lead to some concerns over shell tilting and potential kyphosis that may occur in some patients. ${ }^{[16]}$

The Prestige ${ }^{\circledR}$ cervical disc prosthesis (Medtronic Sofamor Danek, Memphis, TN, USA) is the product of the evolution of the initial Bristol/Cummins disc. The first generation Prestige I/ Frenchay prosthesis had a longitudinal trough instead of the Bristol/Cummins' spherical socket. ${ }^{[17]}$ This semiconstrained arrangement allows a greater degree of translation to occur with rotation. There have been several evolutions in the design of this product. ${ }^{[18]}$ The locking screws used in the Prestige ${ }^{\circledR}$ I and II were eliminated in the fifth generation termed the Prestige-STLP ${ }^{\circledR}$. In the sixth incarnation, currently in clinical use, the material has been changed to a titanium carbide with a plasmapore coating with initial fixation through two rails on either side of midline that are placed into predrilled channels in the endplates. Prestige $\mathrm{LP}^{\circledR}$ has eight sizes with lengths from 14 to $18 \mathrm{~mm}$ and heights from 6 to $8 \mathrm{~mm}$. The plasma-spray titanium coating encourages subsequent bony integration (Figure 2). Cushioning does not occur but aside from ball-and-socket flexion/extension and lateral bending a small degree of translation can also occur because of the configuration of the reciprocating socket placed on the inferior shell. Insertion of this device is relatively straight forward except that spondylotic disease is difficult to address as it is imperative not to remove bony endplate as subsidence may occur. The ideal patient has a soft disc herniation.

The ProDisc-C ${ }^{\circledR}$ (Synthes Spine, Paoli, PA, USA) is an adaptation of the lumbar disc replacement that bears a similar name. ${ }^{[19]}$ The articulating surface consists of a UHMWPE hemispheric surface with a reciprocating cobalt-chrome alloy socket. A midline keel on the vertebral surfaces provides shortterm fixation while a plasma-spray titanium coating encourages osseointegration for longer term stability (Figure 3). The device is a three component product that comes as a single unit and is

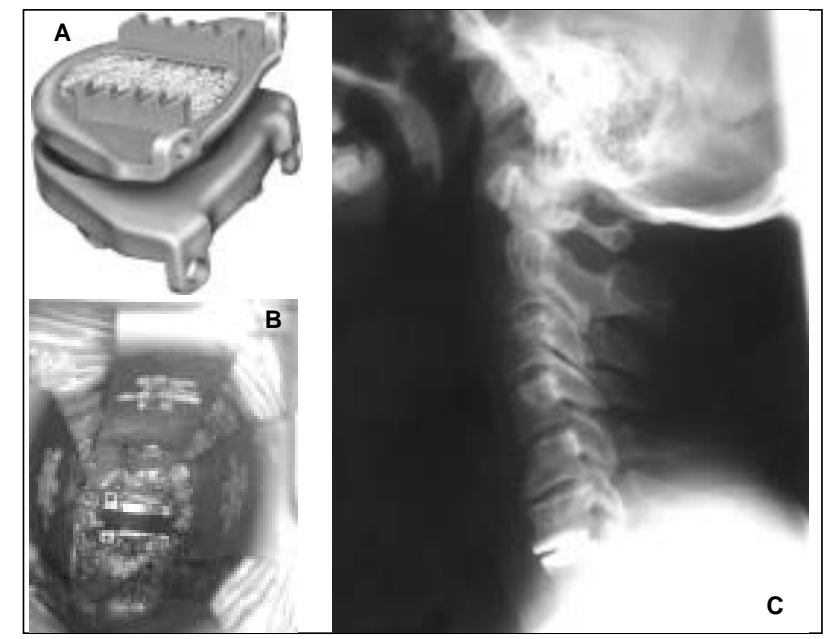

Figure 2: The Prestige ${ }^{\circledR}$ cervical disc prosthesis is a ball-and-socket joint that is relatively constrained $(A)$ which in its latest version requires no screw fixation and is made of titanium carbide (B). Typical postoperative X-rays show the low profile of the prosthesis, which can be used for multiple levels, unlike earlier versions (C) 


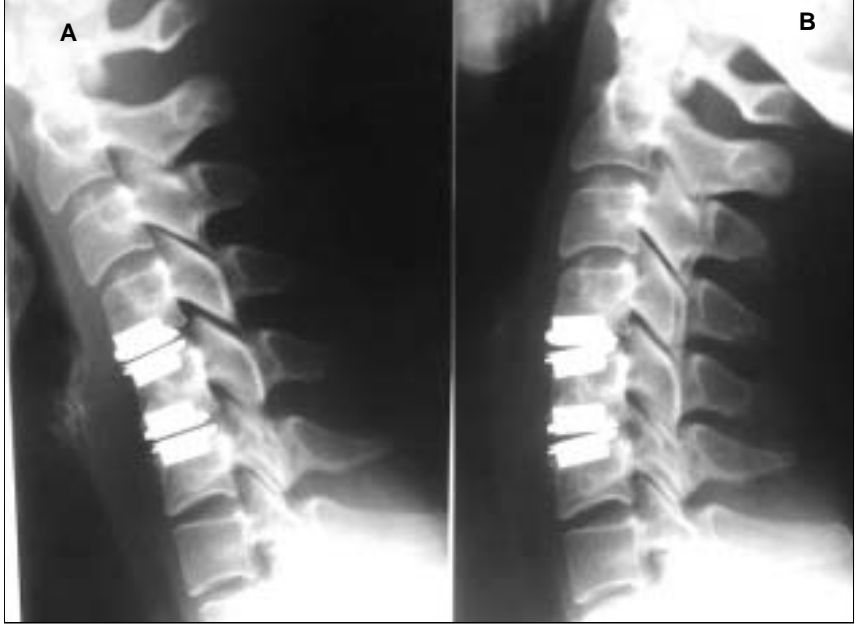

Figure 3: Flexion (A) and extension (B) X-rays of the Prodisc-C $\mathbb{B}$ cervical prosthesis performed at the C4-5 and C5-6 levels. This prosthesis consists mainly of a metal alloy and is a ball-and-socket joint but is more constrained than the Prestige ${ }^{\circledR}$ in that it does not allow for sagittal translation. A midline keel provides initial stability with the central UHMWPE core radiolucent

currently available in 27 sizes that allow for extensive endplate coverage. The device is similar in many respects to the Prestige $\mathrm{LP}^{\circledR}$ but one current limitation is the large amount of artifact noted on postoperative MR scanning with this device due to the presence of cobalt-chrome rather than a polymer or titanium. The differences in MR imaging are demonstrated in (Figure 4) with the degree of artifact limiting its relative efficacy.

The $\mathrm{PCM}^{\circledR}$ (porous-coated motion) prosthesis (Cervitech, Rockaway, NJ, USA) consists of two cobalt-chrome alloy endplates with a large radius UHMWPE bearing surface attached to the caudal component. ${ }^{[20]}$ A titanium/calcium phosphate (TiCaP) surface is electrochemically bonded to the serrated outer surfaces facing the adjacent vertebral bodies. These endplates are also designed to match the curvature of the vertebral surface and maximize loading in the denser lateral vertebral surface. The PCM ${ }^{\circledR}$ is manufactured in a 'press fit' model that requires no supplemental fixation and therefore has no anterior profile and a 'flange fixed' model with anterior screws. This device relies on a gliding motion limited by the facet joints rather than angular rotation found in ball-and-socket devices. The criticism of this device relates to this movement, which arguably may stress the facetjoints more than other designs.

\section{Indications and Results}

The ideal patient for an artificial disc prosthesis has a soft disc herniation causing neurological symptoms or signs, motion at the involved segment with no evidence of instability or hypermobility and an absence of osteoporosis or infection. Normal sagittal alignment with the absence of focal or global kyphosis is desirable. Typically C3-4 to C6-7 can be replaced and the involved space must be able to be radiographically visualized in the operating room using lateral fluoroscopy. Most patients who qualify for a single level anterior cervical decompression and fusion would

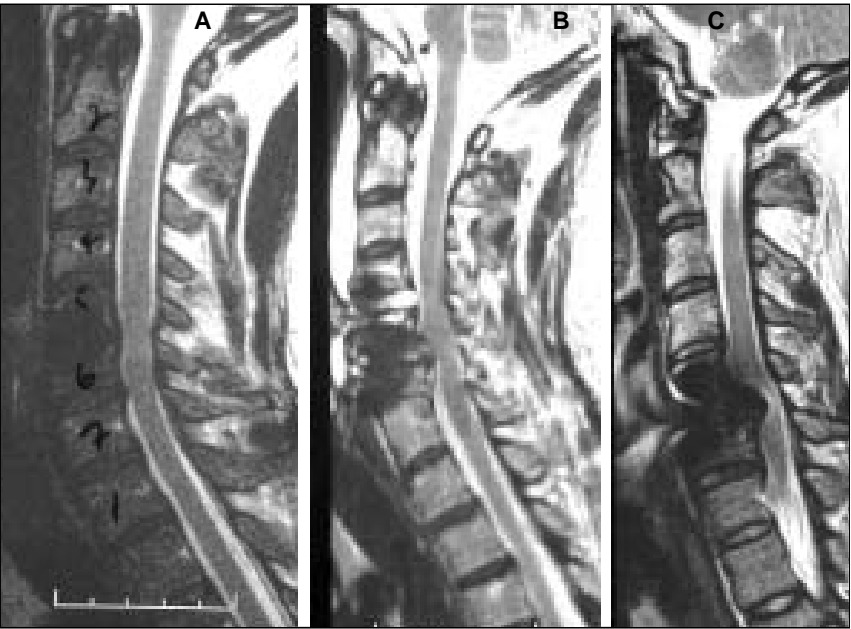

Figure 4: Sagittal T2-weighted MR scanning of a Bryan ${ }^{\circledR}$ disc (A), Prestige $\AA$ (B) and Prodisc-C $\AA$ (C) showing the relative amounts of artifact seen after artificial disc implantation. It is seen that in $4 A$, with implantation of a Bryan ${ }^{\circledR}$ disc prosthesis at C5-6 the adjacent discs and cervical cord at this level are well visualized. In $4 \mathrm{~B}$, with Prestige ${ }^{\circledR}$ implantation at $C_{4}-5$ and $C 5-6$, there is more artifact than the Bryan $\AA$, due to the large amount of titanium present but both $A$ and $B$ have less artifact than that seen in $4 C$ after a single level $C 5-6$ Prodisc-C $\circledast$ implantation where the cobalt chromium alloy makes the MR relatively uninterpretable due to the large amount of metal blooming artifact

qualify for an artificial disc replacement.

Published clinical series of cervical disc arthroplasty predominantly include patients with radiculopathy and myelopathy, secondary to acute disc herniations or degenerative spondylotic change. The initial series describing the Cummins/ Bristol disc included 16 patients with myelopathy, 3 with radiculopathy and 1 with severe neck pain. ${ }^{[10]}$ In reporting the initial use of the Bryan ${ }^{\circledR}$ disc, Goffin described results in 53 patients with radiculopathy and 7 with myelopathy. ${ }^{[14]}$ Goffin et al. reported an expanded series in of 146 patients including 43 two level cases. ${ }^{[21]}$ They further reported 6,12 and 24 months success rates of $90 \%$ (83/92), 86\% (76/89) and $90 \%$ (44/49) for singlelevel surgery. ${ }^{[21]}$ A series reported by Sekhon specifically studied Bryan $^{\circledR}$ disc arthroplasty for cervical spondylotic myelopathy, although some patients had a co-existent radiculopathy. ${ }^{[22,15]} \mathrm{He}$ reported that $91 \%$ of patients had a good or excellent outcome and a statistically significant decrease in Nurick myelopathy scores at a mean followup of 18 months. ${ }^{[22]}$ Duggal et al. examined outcomes in 26 patients implanted with Bryan ${ }^{\circledR}$ discs who had myelopathy and/or radiculopathy, most of which were favourable. ${ }^{[23]}$ Pimenta et al. reported their experience with the PCM ${ }^{\circledR}$ prosthesis in 40 patients with radiculopathy and 13 with myelopathy. ${ }^{[20]}$ This series yielded good or excellent outcomes greater than $90 \%$ at 3, 6 and 12 months. ${ }^{[20]}$ A newly published study analysing the use of ProDisc-C ${ }^{\circledR}$, reported results in 16 patients with 'symptomatic cervical spondylosis'. ${ }^{[24]}$ It included four patients with severe axial neck pain and 12 with established radicuolpathies or myelopathies. Significant postoperative decreases in neck and arm pain intensity and frequency were noted. A similar decrease was recorded in the Oswestry Disability Index. 
A recent report has described the preliminary results of a randomized trial of arthroplasty versus fusion after anterior cervical decompression using the Prestige $\mathrm{II}^{\circledR}{ }^{[25]}$ Intervertebral motion at the treated level was significantly greater in the arthroplasty cohort. Both groups had equal adequate symptom relief at this early stage of the study. To date, reported clinical experience with currently available devices extends only to 2 years post surgery. Early clinical results reflect appropriate patient selection, adequate neural decompression and short-term device safety. Longer followup is needed to determine whether motion preservation translates into decreased adjacent segment disease as well as the long-term safety of arthroplasty prostheses. The current FDA studies have not examined their pooled data but for Bryan $^{\circledR}$ disc and Prestige ${ }^{\circledR}$ II recruiting has finished.

Several reports describe the use of arthroplasty adjacent to a previous fusion. This technique has also been applied to the cervicothoracic junction, an area, which presents unique challenges in management. ${ }^{[26]}$ The Prestige ${ }^{\circledR}$ I/Frenchay prosthesis was placed in 12 patients with cervical radiculopathy and/or myelopathy adjacent to a previous fusion and compared to patients undergoing a second fusion for the same indications. ${ }^{[27]}$ Both groups experienced similar clinical improvement but increased movement at adjacent levels was seen in the fused group. Sekhon has published a case of Bryan ${ }^{\circledR}$ disc arthroplasty for reversal of a previously fused segment at $\mathrm{C} 5 / \mathrm{C} 6$ with restoration of motion. ${ }^{[28]}$ This opens a relative 'Pandora's Box' in terms of potential applications.

Despite the one patient in Cummins series and four in the Prodisc-C series, neck pain is not a widely accepted indication for cervical arthroplasty. However, clinical experience suggests that in patients undergoing cervical disc replacement for other indications, neck pain decreases postoperatively. ${ }^{[22]}$ This would suggest that the pathogenesis of neck pain may include nonmechanical causes, analogous to discogenic lumbar pain. Again, surgery for primary discogenic neck pain using cervical arthroplasty has not yet been done.

It is not yet established whether arthroplasty may have a role in correcting deformity. Pickett et al. studied change in sagittal alignment after Bryan ${ }^{\circledR}$ disc replacement. ${ }^{[16]}$ It was reported that overall sagittal alignment was unchanged, but instrumented levels assume a kyphotic angulation. Kyphotic angulation of shells is not uncommon with this technique but the significance is unknown. Again, further evaluation will be needed to determine any long-term effects from this.

Few early complications have been reported from cervical arthroplasty. Nondevice related complications include those related to the decompression such as postoperative haematoma, dysphagia, dysphonia, spinal fluid leak or persistent symptoms from inadequate decompression. Some series report problems with misplacement or hardware failure. Several instances of paravertebral ossification after Bryan ${ }^{\circledR}$ disc arthroplasty have been reported. This may be prevented by the administration of nonsteroidal anti-inflammatory drugs. Fusion of cervical arthroplasty prosthesis has been reported (Figure 5).
Experience with other joint replacements has created an understanding of the importance of wear debris from the articulating surface in the pathogenesis of late prosthetic failure. Microscopic particulate debris can induce an immune inflammatory response that leads to osteolysis and prosthetic loosening (Figure 6). No uniform testing methodology or consensus standard is currently available for wear analysis. An animal model used to evaluate the Bryan ${ }^{\circledR}$ disc prosthesis demonstrated in vitro wear averaged $1.76 \%$ by weight after 10 million cycles. ${ }^{[29]}$ These results were considered to be within acceptable limits and there was no appreciable inflammatory response in the peri-prosthetic tissues. The authors attributed this to the biologic and material characteristics of polyurethane. The nature of fibro-cartilaginous joints may mean less inflammatory response is seen in the cervical spine compared to relatively pro-inflammatory synovial joints. At this stage, accelerated wear and particle debris formation leading to loosening of the devices does not appear to be an issue. The devices may last the lifetime of the patient. ${ }^{[30]}$ Again, longer term evaluation is
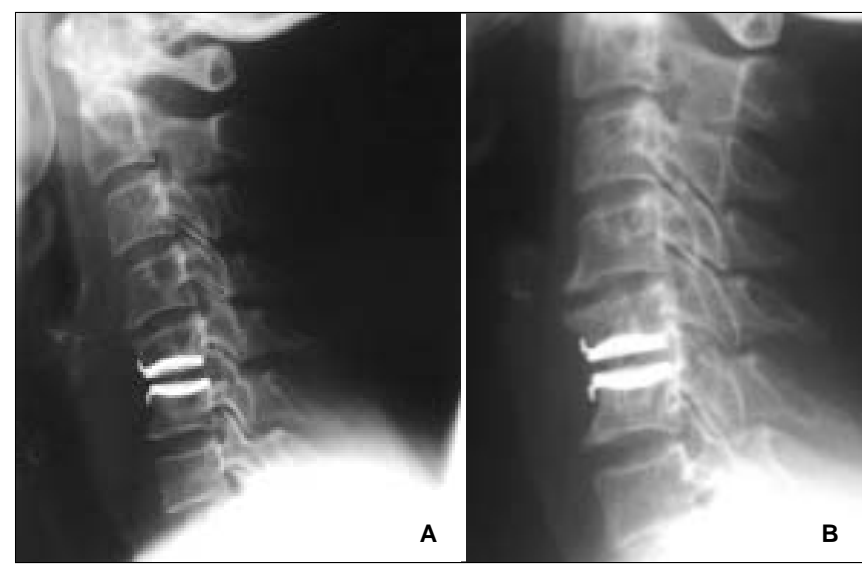

Figure 5: This woman underwent C5-6 Bryan ${ }^{\circledR}$ disc arthroplasty (A) and 17 months later fused across this motion segment (B) with bridging osteophyte seen posteriorly. As follow-up periods get longer, complications such as this will be seen

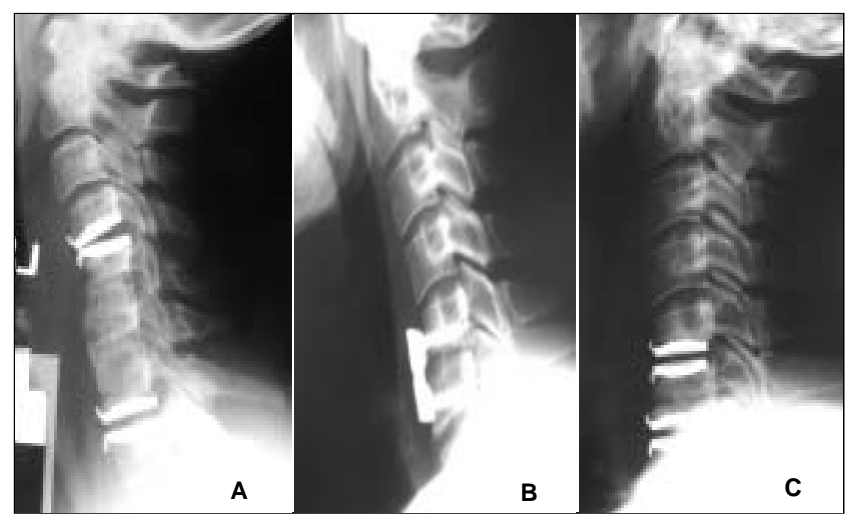

Figure 6: Pushing the limits of disc replacement, arthroplasty has been performed at the cervicothoracic junction (A). Another marginal indication includes the patient in $(B)$ who at referral had undergone a C5-6 allograft and plating and subsequently went on to have reversal of the C5-6 fusion with placement of a cervical arthroplasty that restored motion (C) 
needed to ascertain the incidence of long-term complications.

\section{Issues for further research}

Cervical arthroplasty aims to maintain cervical motion after anterior decompression. It is hoped that motion preservation will decrease the incidence of adjacent level disease. Whether this eventuates remains the major issue for further research. The last 10 years have seen significant changes in the design and materials of cervical arthroplasty prostheses. Continuing research into cervical biomechanics will lead to refinements of the design to better mimic natural motion. Newer biomaterials will improve wear characteristics and encourage superior osseointegration. Bioengineered cartilage, bone or integrated growth factors may offer 'natural' alternative materials for prostheses.

Arthroplasty has predominantly been used for radiculopathy and myelopathy, secondary to acute disc herniations or degenerative spondylotic change. As experience grows, new and expanded indications may be realized. As discussed earlier, disc replacement for neck pain, deformity correction or revision of earlier fusion are emerging as other potential indications. No reports of disc arthroplasty used in trauma have been reported but may be another area for study.

Cervical arthroplasty focuses on the anterior approach to cervical disease. Further development of posterior surgical devices or facet joint replacements may offer a total spine arthroplasty solution but nevertheless the era of motion preservation has been entered.

\section{Conclusions}

The emergence of cervical arthroplasty has changed the face of cervical spinal surgery. In contrast to the traditional philosophy of attaining rigid fusion, cervical disc replacement aims to maintain intervertebral movement to avoid the complications and limitations associated with arthrodesis. It is hoped that preservation of movement will decrease stress on adjacent vertebral levels and lead to a reduced incidence of adjacent segment degeneration. Multiple prostheses with varying design principles and material applications are available. While early results are promising, longer term evaluation will determine whether theoretical advantages translate into clinical benefits.

\section{References}

1. Pickett GE, Van Soelen .J, Duggal N. Controversies in Cervical Discectomy and Fusion: Practice Patterns Among Canadian Surgeons. Can J Neurol Sci 2004;31:478-83.

2. Phillips FM, Carlson G, Emery SE, Bohlman HH. Anterior Cervical Pseudarthrosis. Natural History and Treatment. Spine 1997;22:1585-9.

3. Pospiech J, Stolke D, Wilke HJ, Claes LE. Intradiscal Pressure Recordings in the Cervical Spine. Neurosurgery 1999;44:379-84.

4. Eck JC, Humphreys SC, Lim TH, Jeong ST, Kim JG, Hodges SD, et al. Biomechanical
Study on the Effect of Cervical Spine Fusion on Adjacent-Level Intradiscal Pressure and Segmental Motion. Spine 2002;27:2431-4.

5. Hilibrand AS, Carlson GD, Palumbo MA, Jones PK, Bohlman HH. Radiculopathy and Myelopathy at Segments Adjacent to the Site of a Previous Anterior Cervical Arthrodesis. J Bone Joint Surg Am 1999;81:519-28.

6. Goffin J, Geusens E, Vantomme N, Quintens E, Waerzeggers Y, Depreitere B, et al. Long-Term Follow-Up After Interbody Fusion of the Cervical Spine. J Spinal Disord Tech 2004;17:79-85.

7. Vaccaro AR, Chiba K, Heller JG, Patel TC, Thalgott JS, Truumees E, et al. Bone Grafting Alternatives in Spinal Surgery. Spine J 2002;2:206-15.

8. Fernstrom U. Arthroplasty With Intercorporal Endoprothesis in Herniated Disc and in Painful Disc. Acta Chir Scand Suppl 1966;357:154-9.

9. Reitz H, Joubert MJ. Intractable Headache and Cervico-Brachaligia Treated by Complete Replacement of Cerical Intervertebal Dises With a Metal Prosthesis. S Afr Med .J 1964;38:881-4.

10. Cummins BH, Robertson JT, Gill SS. Surgical Experience With an Implanted Artificial Cervical Joint. J Neurosurg 1998;88:943-8.

11. Mummaneni PV, Haid RW. The Future in the Care of the Cervical Spine: Interbody Fusion and Arthroplasty. Invited Submission From the Joint Section Meeting on Disorders of the Spine and Peripheral Nerves, March 2004. J Neurosurg Spine 2004; $1: 155-9$

12. Bogduk N, Mercer S. Biomechanies of the Cervical Spine. I: Normal Kinematies. Clin Biomech (Bristol, Avon.) 2000;15:633-48.

13. Oskouian RJ, Whitehill R, Samii A, Shaffrey ME, Johnson JP, Shaffrey CI. The Future of Spinal Arthroplasty: a Biomaterial Perspective. Neurosurg Focus 2004; 17 :E2-

14. Goffin J, Casey A, Kehr P, Liebig K, Lind B, Logroscino C, et al. Preliminary Clinical Experience With the Bryan Cervical Dise Prosthesis. Neurosurgery $2002 ; 51: 840-5$

15. Sekhon LH. Cervical Arthroplasty in the Management of Spondylotic Myelopathy. J Spinal Disord Tech 2003;16:307-13.

16. Pickett GE, Mitsis DK, Sekhon LH, Sears WR, Duggal N. Effects of a Cervical Dise Prosthesis on Segmental and Cervical Spine Alignment. Neurosurg Focus 2004;17:E5-

17. Wigfield CC, Gill SS, Nelson RJ, Metcalf NH, Robertson JT. The New Frenchay Artificial Cervical Joint: Results From a Two-Year Pilot Study. Spine 2002;27:244652.

18. Traynelis VC. The Prestige Cervical Disc Replacement. Spine J 2004:4:310S-4S

19. DiAngelo D J, Foley KT, Morrow BR, Schwab JS, Song J, German JW, et al. In Vitro Biomechanies of Cervical Disc Arthroplasty With the ProDisc-C Total Dise Implant. Neurosurg Focus 2004;17:E7-

20. Pimenta L, McAfee PC, Cappuccino A, Bellera FP, Link HD. Clinical Experience With the New Artificial Cervical PCM (Cervitech) Dise. Spine J 2004;4:315S$21 \mathrm{~S}$.

21. Goffin J, Van Calenbergh F, van Loon J, Casey A, Kehr P, Liebig K, et al. Intermediate Follow-Up After Treatment of Degenerative Disc Disease With the Bryan Cervical Disc Prosthesis: Single-Level and Bi-Level. Spine 2003;28:2673-8.

22. Sekhon LH. Cervical Arthroplasty in the Management of Spondylotic Myelopathy 18-Month Results. Neurosurg Focus 2004;17:E8-

23. Duggal N, Pickett GE, Mitsis DK, Keller JL. Early Clinical and Biomechanical Results Following Cervical Arthroplasty. Neurosurg Focus 2004;17:E9-

24. Bertagnoli R, Yue J.J, Pfeiffer F, Fenk-Mayer A, Lawrence JP, Kershaw T, et al. Early Results After ProDisc-C Cervical Disc Replacement. J Neurosurg Spine 2005;2:403-10.

25. Porchet F, Metcalf NH. Clinical Outcomes With the Prestige II Cervical Disc: Preliminary Results From a Prospective Randomized Clinical Trial. Neurosurg Focus 2004;17:E6-

26. Sekhon LH. Cervicothoracic Junction Arthroplasty After Previous Fusion Surgery for Adjacent Segment Degeneration: Case Report.[Report]. Neurosurgery $2005 ; 56$.

27. Wigfield C, Gill S, Nelson R, Langdon I, Metcalf N, Robertson J. Influence of an Artificial Cervical Joint Compared With Fusion on Adjacent-Level Motion in the Treatment of Degenerative Cervical Dise Disease. J Neurosurg Spine 2002;96:1721.

28. Sekhon LH. Reversal of Anterior Cervical Fusion With a Cervical Arthroplasty Prosthesis. J Spinal Disord Tech 2005;18:S125-8.

29. Anderson PA, Rouleau JP, Bryan VE, Carlson CS. Wear Analysis of the Bryan Cervical Disc Prosthesis. Spine 2003;28:S186-94.

30. Anderson PA, Rouleau JP, Toth JM, Riew KD. A Comparison of Simulator-Tested and -Retrieved Cervical Disc Prostheses. Invited Submission From the Joint Section Meeting on Disorders of the Spine and Peripheral Nerves, March 2004. J Neurosurg Spine 2004;1:202-10. 